\title{
Untraditional Factors Discussion on Modern Freehand Landscape Painting Techniques
}

\author{
Xiaochun Hu*, Qiang Meng \\ School of Art, Yulin University, Yulin, China \\ Email address: \\ 986794461@qq.com (Xiaochun Hu),278862218@qq.com (Qiang Meng) \\ ${ }^{*}$ Corresponding author
}

To cite this article:

Xiaochun Hu, Qiang Meng. Untraditional Factors Discussion on Modern Freehand Landscape Painting Techniques. International Journal of Literature and Arts. Vol. 5, No. 4, 2017, pp. 35-39. doi: 10.11648/j.ijla.20170504.13

Received: June 18, 2017; Accepted: July 12, 2017; Published: August 7, 2017

\begin{abstract}
The freehand landscape painting, one of Chinese painting forms, is based on Chinese traditional culture development. And modern western painting techniques affect Chinese painting a lot, which make Chinese painting present a new form. So through research and analysis, in order to expand more developing space for Chinese freehand landscape painting, it is significant to consider how to combine western culture with it and what need to carry on or give up under the trend of multi-culture.
\end{abstract}

Keywords: Freehand Landscape Painting, Western Painting, Pen and Ink

\section{Introduction}

Chinese traditional freehand landscape painting only existed as a background of painting before Wei, Jin, Northern and Southern dynasties. And at that time, Chinese painting developed quickly and in Sui and Tang dynasty, it got a further development. Then at Song dynasty, it reached a peak to be a big painting of Chinese painting. Then, this prosperous continued before Ming and Qing dynasty, and then it presents a conservative technique trend which is represented by 'Four Wang' whose paintings are far away from normal life. Since the twentieth century, the new generation of artists make a great creation and improvement for new performance of language and form. And the most famous artists are Beihong $\mathrm{Xu}$ and Fengmin Lin, who not only combined western realistic painting with Chinese paintings and also found a new development direction of Chinese paintings. So his idea affected freehand landscape painting on performance language and thought that transformed it from traditional form to modern form.

In the 21th century, it will be a question that how to develop Chinese traditional painting. As for this, it have to use scientific attitudes and dialectical thinking methods to analyze problems. Marxism thinks, the economic base determines the superstructure, superstructure is cooperated with economic base. Therefore, it should clearly recognize the meaning and importance of establishing a new system of socialist market economy [1]. It is given priority to public ownership, other forms of ownership and auxiliary system, which is adapted to the superstructure (referring to drawing art) that will also be presented a trend of diversification of main and auxiliary. The so-called the Lord is time spirit and the civilization construction spirit, that advocates the realism in the form. So-called auxiliary means more painters in China on the basis of inheriting traditional art and beneficial ingredient, extensive absorption of various characteristics of the various genres of modern western painting, technique of expression to enrich his own painting language, that reflect better than the various social strata's aesthetic requirements.

\section{Concepts of Sketching and Modeling in Modern Freehand Landscape Painting}

Long before, pencil sketch is the basic course in every art university, the reason is that its performance and idea affect modern landscape paintings on creation and forming. Modern painting artists [2], who broke traditional conception of painting and created many paintings which can reflect the 
natural landscape scenery.

Chinese traditional landscape painting is through line painting skills to express emotions of artists and do not pursue a similarity with scenery and items to use a scatter perspective method of paintings composition. The famous representative is $\mathrm{Fu}$ Chun Shan Ju Painting by Gongwang Huang in Yuan dynasty, whose painting skill is perfect. And through traditional landscape paintings, in order to persue concave and convex of items, basically, Chinese traditional landscape painting does not show image shadows [3]. Nevertheless, as for western painting skills, it is significant to show natural landscape. Therefore, modern Chinese artists use traditional Chinese painting skills and additionally draw lessons from western modeling technique of expression and creation.

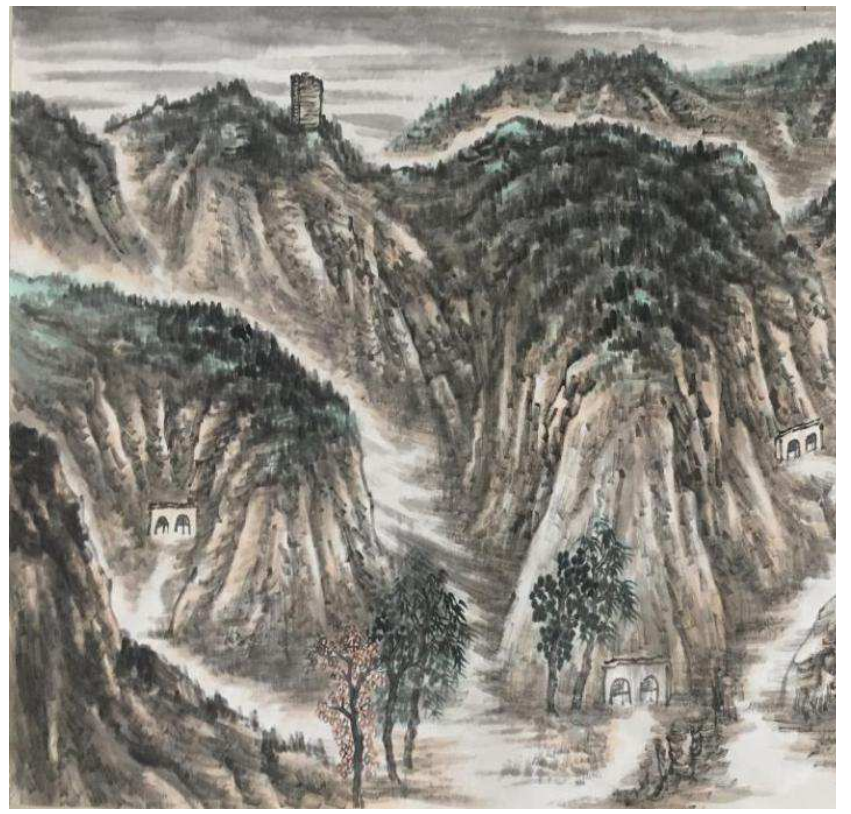

Figure 1. Freehand Landscape Painting Techniques.

In modern Chinese paintings time, Keran $\mathrm{Li}$ is a famous artists who combine Chinese and western painting skills together and apply lines for images of structure with a strong shape. Additionally, his paintings meet contemporary aesthetic and create a new style of modern freehand landscape brushwork paintings [5].

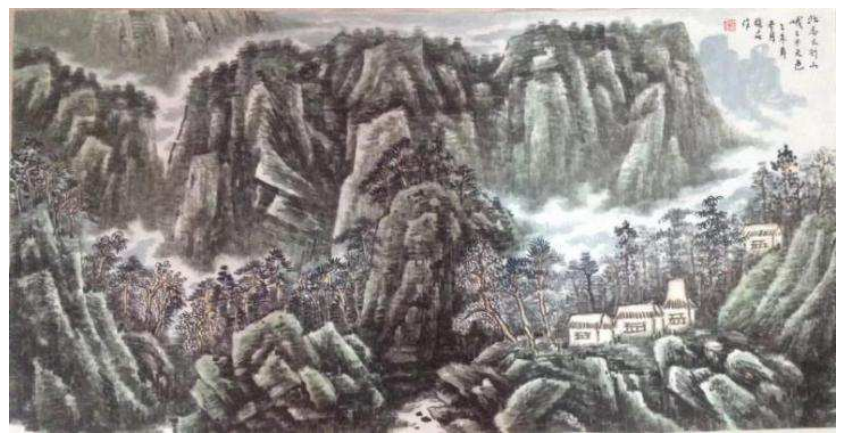

Figure 2. Freehand Landscape Painting Techniques.

\section{The Infiltration of Contemporary Landscape Painting Color Modeling Concepts}

In common, color could bring about a strong emotional resonance and attract the attention of the viewers because of its strong visual impact and colorful changes. But in traditional Chinese landscape paintings, the pen and ink is more important than colors also it can not present the relationship light and color. Therefore, since western paintings art entering China, contemporary landscape painting color modeling concepts affect Chinese painting skills significantly. In color respect, impressionists paint and present a scene carefully through the perspective of the color changes. It not only make a great contribution to western contemporary freehand brushwork art but also to Chinese landscape paintings.

Therefore, there are Lingnan style representatives Jianfu Gao and Qifeng Gao who apply the Japanese painting skills to traditional Chinese paintings so that they created a new painting style [4]. And another famous representative is Fengmian Lin, who devoted himself to combine spirits home and aboard through freehand brushwork paintings. His main artistic achievement is successfully introduced color art on Chinese art paper with a light feeling through his landscape paintings so that it radically changed the face of Chinese painting.

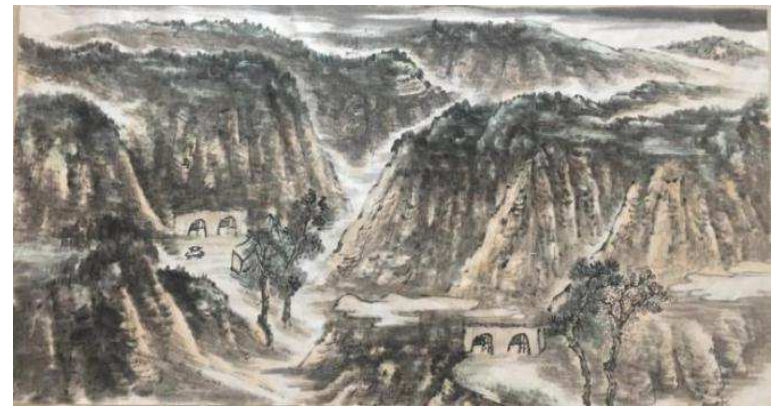

Figure 3. Freehand Landscape Painting Techniques 2.

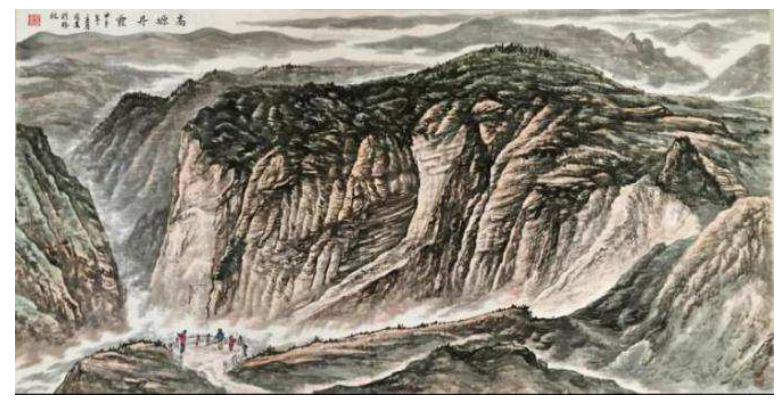

Figure 4. Freehand Landscape Painting Techniques 3.

And his paintings, such as Autumn woods, Autumn scenery, Mount Huangshan, fully demonstrate the charm of color. He often set the color from the overall effect of the picture and guarantee the priority of ink. According to his paintings, dark colors often use to serve as a foil to bright colors, such as green, yellow and orange which break the tradition of white background in the paintings. Another 
representative, Daqian Zhang, create a new splashed-ink method. So that Guanzhong $\mathrm{Wu}$ learn from him and then achieve a great success in traditional paintings [6].

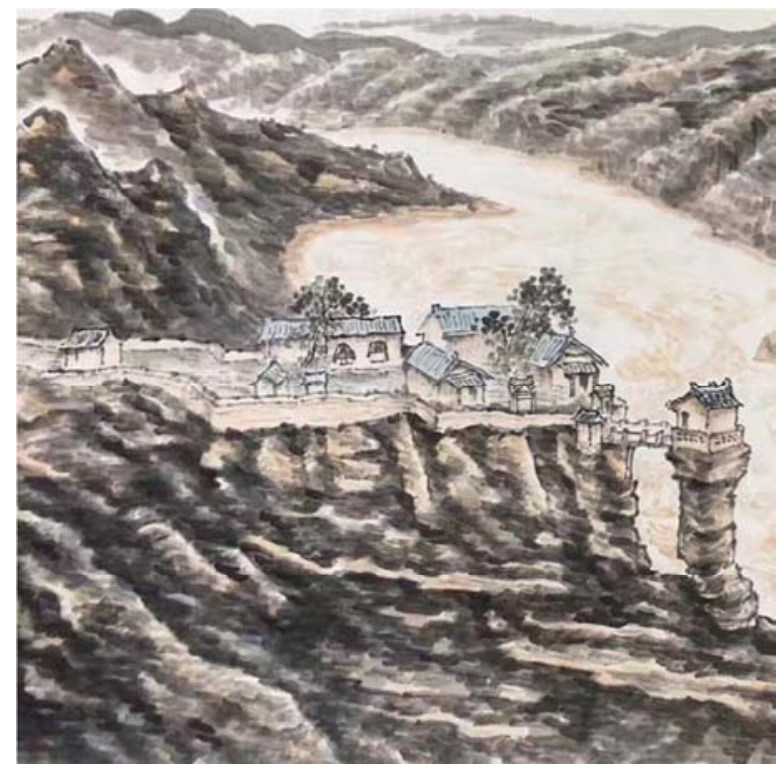

Figure 5. Freehand Landscape Painting Techniques 2.

If contemporary freehand brushwork in traditional Chinese paintings only depend on the western concept of color, it will lose the nationally artistic features. Therefore, it is important to combine the culture home and abroad to create the national color art performance with Chinese characteristics.

\section{The Establishment of the Concept of Contemporary Freehand Brushwork Painting During Its Creation}

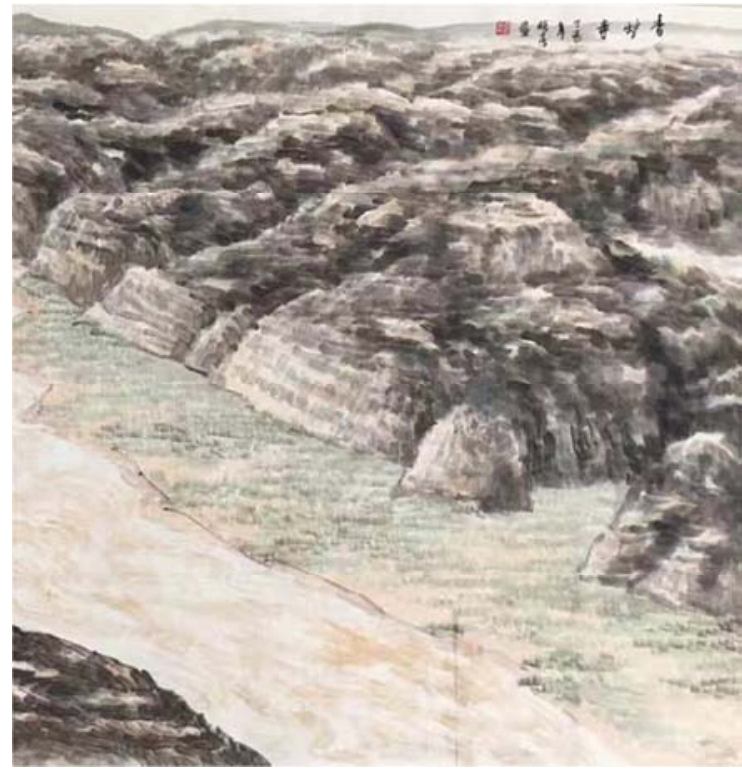

Figure 6. Freehand Landscape Painting Techniques.

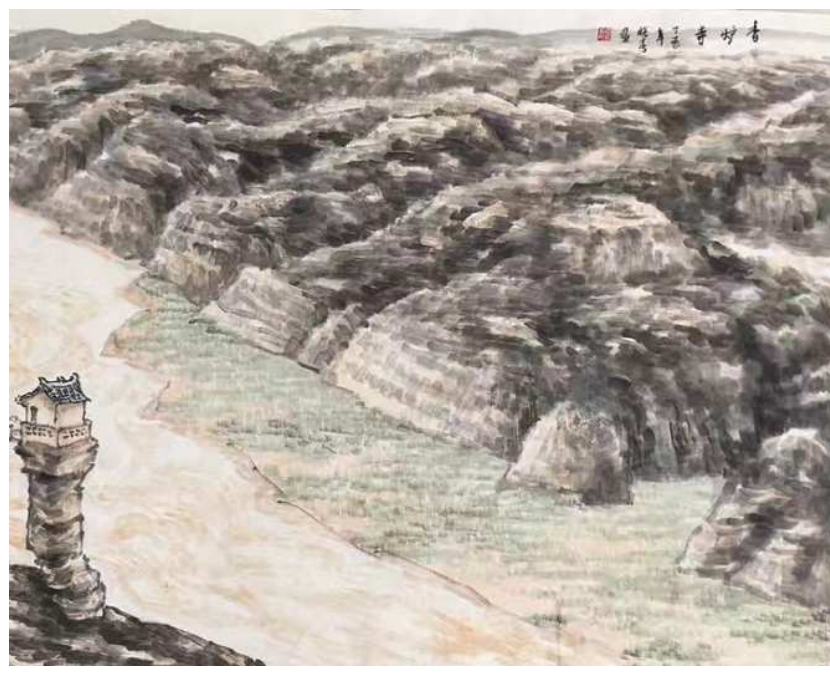

Figure 7. Freehand Landscape Painting Techniques.

In traditional Chinese landscape paintings, it is significant to observe and experience the life so that it can describe and paint the scenery by sense not depicting. It focus on express the motion of artists and subjective feeling. So in traditional Chinese painting, majority of artists created their paintings at home so that also make the Chinese paintings in symbolic expression language [7].

Therefore, imitation of traditional western realism sketch view greatly affect on Chinese landscape painting expression. Keran Li said, sketch is the key to describe the familiar subjects. Every art painting should develop with time and reflect the life by observing, experiencing, researching and analysis. Contemporary Chinese freehand brushwork painters often use scenery creation method through the absorption of the concept of western painting.

This method can find out the internal performance of life by observing life carefully so that painters can look for the inspiration of paintings and own expression language and composition method. Certainly, this method is not a simple imitation, but a new creation of images of the scene.

The influence of modern western art thought that the development of Chinese painting runs through the whole modern history. Chinese traditional painting absorbs and borrows from western art is also an irresistible trend. Therefore, we should "take the essence and discard the dregs" in the problem of absorption and reference. Only in this way it can made breakthrough in the development of Chinese painting to not only create a retains the character of Chinese painting but also on behalf of the modern society.

Table 1. Freehand Landscape Painting Techniques.

\begin{tabular}{ll}
\hline Method 1 & Skill 2 \\
\hline 1 & Chinese painting \\
2 & creation of images of the scene \\
3 & normal life and spiritual life \\
4 & modern people \\
5 & reformation \\
6 & blanks and lofty \\
7 & reality \\
\hline
\end{tabular}


In a word, after one thousand years development, landscape paintings has became a highly stylized painting system. Because of the nature's infinite change, artists pursue the art infinitely so that artists could create more new landscape paintings which can reflect normal life and spiritual life of modern people. Keran $\mathrm{Li}$ said, if people have left the nature (including society) and the tradition, it is impossible to create anything. He hope that everyone can learn more knowledge from them. This idea is worth to study forever [8].

\section{The Non-traditional Language Structure in Today's Impressionistic Landscape Painting}

\subsection{Focus on the Screen Form and the Painting Improvement}

The traditional chase for landscape painting is "poetry, calligraphy and painting should be all expressed", "put calligraphy into the painting" and "calligraphy and painting from the same source". When the painting and the calligraphy are in the same structure, the poetry and the painting are in the same artistic conception and assisted by the wonderful stamp, the integration of language art of the traditional landscape painting can be formed. The pen and ink is the essence in Chinese painting [9]. Today's multi-aesthetic context means freedom, tolerance and selection. The existence of multi-aesthetic context and the multi-form of art can help people open their spiritual vision, and can help the art to become more freedom, which can improve the development for today's Chinese landscape painting. Modern civilization and modern western art are great impact for traditional humanities landscape painting, the loss for the ability of calligraphy and the weakness of writing poetry make today's painter can be compared with the ancient ones. Therefore, for today's painter, they should focus on tension in the screen and to explore today's property and morphology of ink performance language.

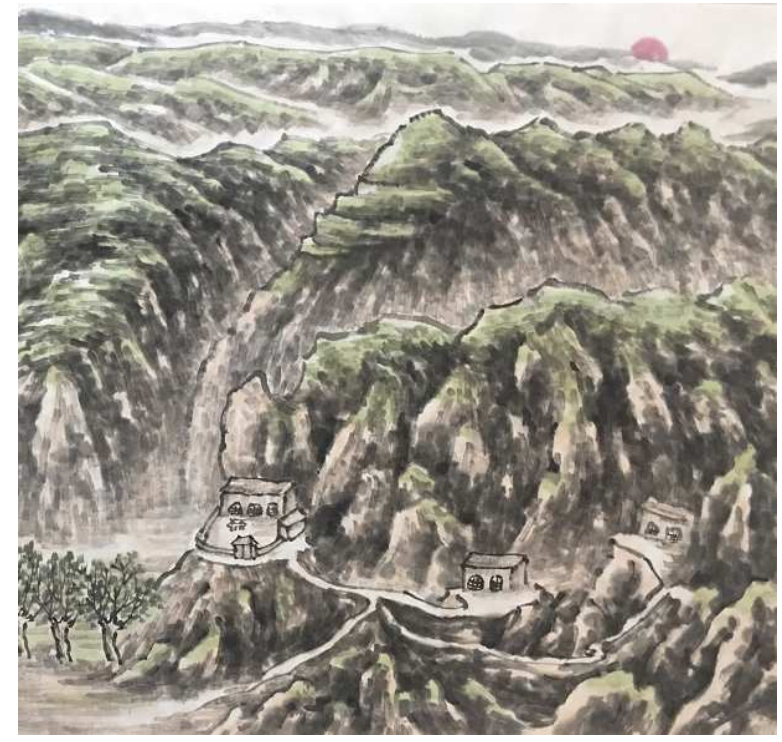

Figure 8. Freehand Landscape Painting Techniques.
Today's landscape painting appears independent modeling meaningful colors, layout increasingly flexible and personalization. At the same time, the realistic, decorative, highlighting the popular taste and elegance of expression are all existed.

There is also a purely contemporary landscape painting process in landscape painting's performance and painters can highly generalized to make the natural scenery just as a symbolic form of abstract expression, which can focus on the painting itself from the formation, ink, color and some other languages.

Zhenkuan Cai, a contemporary landscape painter, focus on the exploration of the form of ink and get a unique expression. Although he has rich cultural heritage, he just use today's art language to express the heavy and majestic of the yellow lands [14]. Also, he adds his calligraphy into his painting, the expression of ink is mainly by points and use different lines to make up the split the plane in the paintings, which make up the overall visual image of the picture. He totally get rid of the bound of natural landscape paintings and express in a symbolic way so that everything can be regarded as carriers for his enthusiasm [10]. In his paintings, there is nearly no blanks and lofty perspective are often used to show a vast and expanse feeling. Another painter, Youfu Jia, his paintings look beyond reality and higher than the natural beauty and spiritual shock. He use passion ink to show a powerful and broad feeling in his changeable picture.

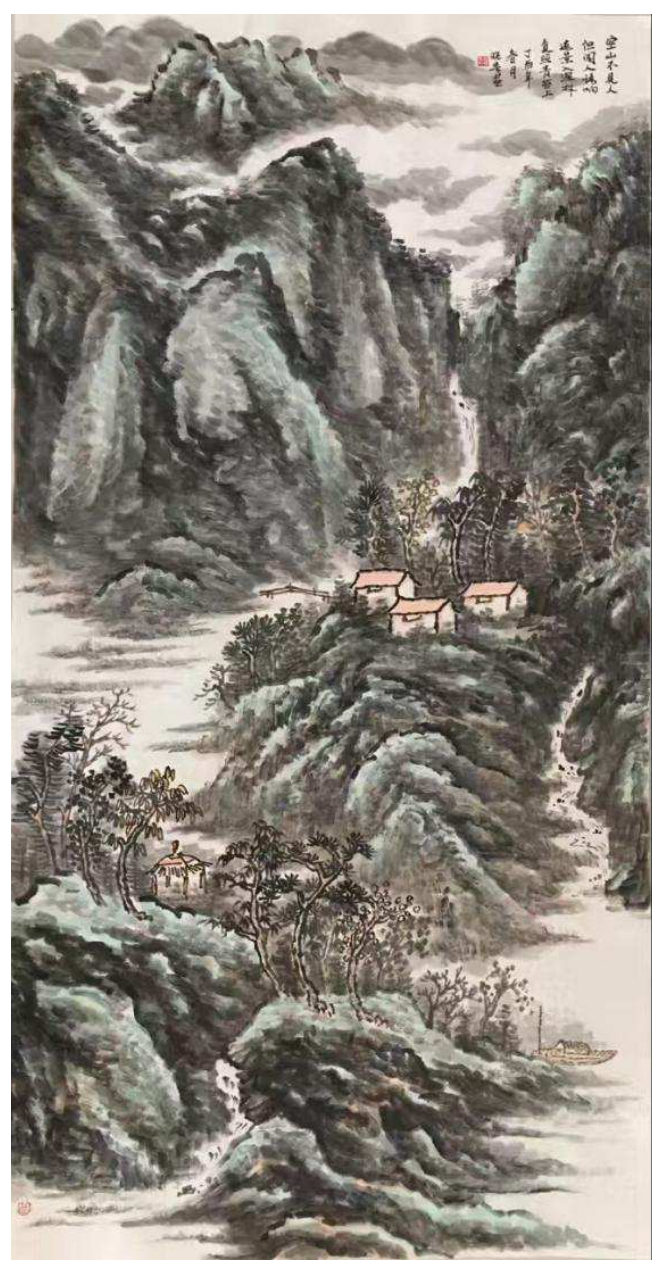

Figure 9. Landscape painting by Xiaochun Hu. 


\subsection{The Application of Modern Ink and New Material}

These painters use western modernism to reform Chinese painting, which adds many performances in screen such as kneading, rubbing, Figure ht, stick and other techniques, even revert ink into purely decorations and materials to form great visual tension screens.

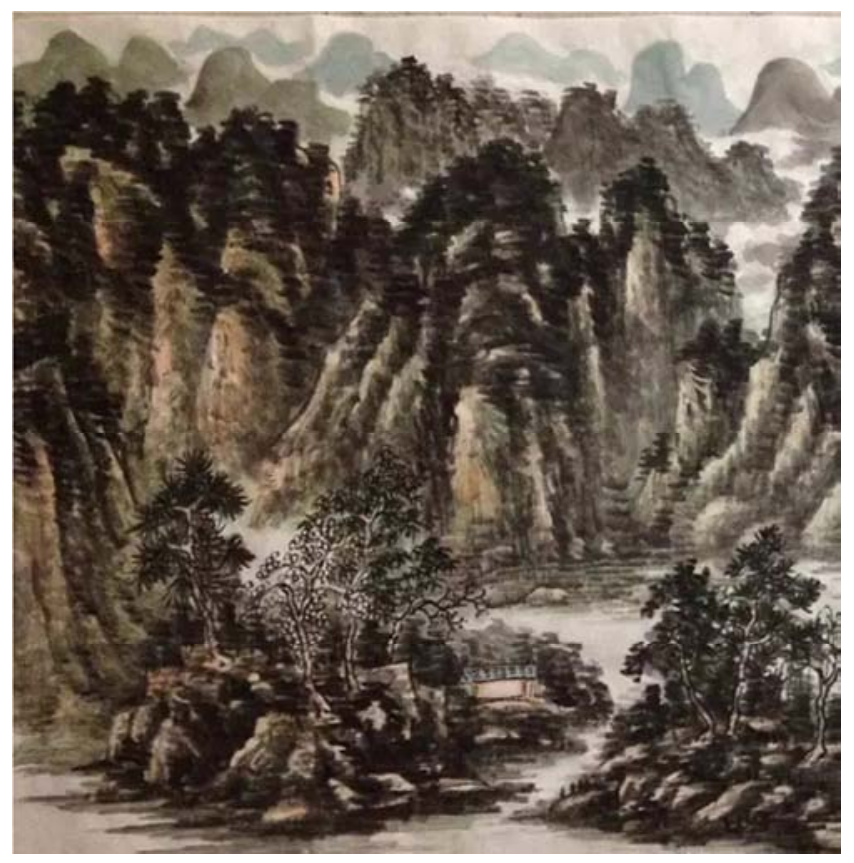

Figure 10. Freehand Landscape Painting Techniques.

Painter Guanzhong Wu proposed "ink means zero" in his ink expression words, and put into application, which caused a debate in painting art. Painter Wenda Gu also use a abstract ink to express the landscape, also often use the combination of words to express a surreal feeling. He also use materials for painting directly, which reform Chinese paintings to a decorative art [11].

\subsection{Pay Attention to Absorbing Cultures Form Folk}

Modern landscape painters begin to express the unique geographical landscape features and pay attention to absorbing nutrients from the folk, and put the most simple, the most original and the most innocent feelings from the folk to express the reformation in the Chinese landscape paintings [12]. Among all these painters, Lu Sih, Wenxi Liu, Zhenkuan Cui can express the yellow land style, and Shuli Han, Youxin Yu can express the Tibet style [15]. Take Shuli Han as an example, his paintings not also keep the snow style, but also has the recall and thinking for the age, which forms his unique art expression language, symbols and style, show the magic and holly for the Big West and earns spiritual resonance for today's people.

\section{Conclusion}

Chinese landscape paintings combine culture at home and abroad, which also unite modern cultural spirits. Therefore, it brings about a lot of free opportunities to promote the pluralism of Chinese landscape paintings also it brings about a lot confusions for modern artists. So they should be with a calm attitude to observe life and create new paintings more sincerely, comprehend subtileness of Chinese landscape paintings that they could create an unique aesthetic paintings gradually.

\section{Acknowledgements}

I should express my thanks for funding support of School of Art, Yulin University and the funding number is $2017 \mathrm{Z} 123$.

\section{References}

[1] Cui Yue, The influence of western art on Chinese painting, Book and Painting World, 2015, the 3rd issue of | cui yue guangdong academy.

[2] Ye Zhongfeng, On the influence of modern western art thought on Chinese painting, 2016 (2): 12-13.

[3] Xiaoming Xiu, The influence of western painting art on the development of Chinese painting, Group papers, 2016, pp 27.

[4] Jerome Silbergeld. 1987. Chinese Painting Studies in the West: A State-of-the-field Article, pp 12-14.

[5] Max Loehr. 1964. Some Fundamental Issues in the History of Chinese Painting, pp 121-134.

[6] Yang Huidan, The influence of western art thoughts on the painting style of the first three countries of the republic of China, The study of central plains culture, 2009, 17 (1): 160-161.

[7] Li xin, Zhao Liping, Western traditional color culture and its influence on Chinese painting, 2015 (5): 216-218.

[8] Zhang Tianshuang, The influence of modern western painting on the color of Chinese painting, Great view of fine arts, 2014 (8): 51-51.

[9] Gu Mengchen, On the influence of scientific thought and western literary methodology on the traditional art - taking Chinese painting as an example, Literary and artistic theory, 2016 (1): 184

[10] Fong Wen. 1963. Chinese Painting: A Statement of Method, 2002, pp. 73.

[11] Xf Yue, A brief analysis of the influence of western "realism" on the expression of Chinese painting and painting, Central academy of arts University, 2015.

[12] Joseph Levenson, 1957, The Amateur Ideal in Ming and Early Ching Society: Evidence from Painting.

[13] Lijing Ge, National is the world -- the influence of Western painting on the composition of Chinese painting, Art life, Yiyuan Wenhai, (2), 2016.

[14] Huang Ronghui, The integration and influence of Chinese oil painting and traditional Chinese painting, Art appreciation, 2017 (1).

[15] $\mathrm{Xu} \mathrm{Yu}, \mathrm{On}$ the innovation of contemporary Chinese painting and the integration of Chinese and Western painting, Jilin Arts College, 2015. 